\title{
AN EFFECT OF THE FEMALE GENOTYPE ON SPERM TRANSPORT IN MICE
}

\author{
A. NICOL AND ANNE MaLAREN* \\ Department of Genetics, University of Edinburgh, Edinburgh EH9 $3 \mathcal{J N}$
}

\section{(Received 14th February 1974)}

Differences between inbred strains of mice in the timing of the first cleavage division were first detected by Braden (1958). One such difference, analysed by Krzanowska (1964), was found to be due to the genetic constitution of the male. In comparisons among two inbred strains, an $F_{1}$ group and an outbred strain, fertilization occurred earlier after matings with $F_{1}$ than with inbred males, and earlier still with outbred males, irrespective of the genotype of the female.

On the other hand, McLaren \& Bowman (1973) found that a difference in the timing of development of C57BL and $\mathrm{C} 3 \mathrm{H}$ embryos was mediated entirely through the mother. Development in C57BL females was 3 to $4 \mathrm{hr}$ ahead of development in $\mathrm{C} 3 \mathrm{H}$ females, whether the females were mated to males of their own or the other strain. The difference was already manifest at the pronuclear stage of fertilization, even when the time of mating was controlled to within an hour. The present work, using the same strains of mice, was designed to determine whether the difference affected activation or penetration of the egg, or some aspect of sperm transport.

Inbred mice of the strains $\mathrm{C} 57 \mathrm{BL} / \mathrm{McL}$ and $\mathrm{C} 3 \mathrm{H} / \mathrm{Bi} . \mathrm{McL}$ were used. The female mice were put into the cages of the males at 09.00 hours and were checked for vaginal plugs at 10.00 hours. To follow the course of fertilization, the mated female mice were killed at intervals after 10.00 hours. The cumulus clumps were liberated from the oviducts in phosphate-buffered saline (Dulbecco A) by rupturing the ampullae with watchmakers forceps. The cumulus cells were removed in $0.05 \%$ hyaluronidase solution and the eggs were transferred through phosphate-buffered saline (PBS) into $3 \%$ glutaraldehyde in 0.1 M-phosphate buffer, $\mathrm{pH} 7 \cdot 2$. The eggs were refrigerated in fixative for 2 to $24 \mathrm{hr}$ before examination. At all times, eggs from individual mice were kept separate. The uteri were always examined at autopsy to verify the presence of spermatozoa.

For examination, the fixed eggs were transferred to $\mathrm{PBS}$ in a depression slide and observed through a Leitz $\times 50 \mathrm{H}_{2} \mathrm{O}$-immersion objective using Zeiss Nomarski optics. The eggs were scored for the numbers of spermatozoa associated with them, the presence of spermatozoa in the vitelli and the presence of pronuclei. As a check and occasionally for further identification, the eggs were then stained in lactic aceto-orcein and observed under bright-field illumination.

To investigate the numbers and distribution of spermatozoa in the upper

* Agricultural Research Council Unit of Animal Genetics. 
female reproductive tract, intact oviducts including the uterotubal junction were fixed in Bouin's fluid at specific times after mating. Serial paraffin-wax sections at $7 \mu \mathrm{m}$ were stained in Giemsa and mounted in Canada Balsam. The numbers of spermatozoa and their distribution were noted, either on every section (six oviducts) or on every fifth section (ten oviducts).

The results of examining ovulated eggs from the two strains of mice at different times after mating are shown in Table 1. The penetration of spermatozoa into the vitellus was clearly at least 2 to $3 \mathrm{hr}$ later in $\mathrm{C} 3 \mathrm{H}$ females than in G57BL fermales. The difference in proportion of eggs penetrated is significant for both within-strain and between-strain matings, confirming the femaledependence of the effect. The mean number of spermatozoa associated with each egg (stuck to or embedded in the zona pellucida, in the perivitelline space or in the vitellus) increased with time in both strains, but was consistently lower in $\mathrm{C} 3 \mathrm{H}$ females. At $5 \mathrm{hr}$ after mating, less than one spermatozoon per egg was detected in $\mathrm{C} 3 \mathrm{H}$ females, compared with two per egg $3 \mathrm{hr}$ after mating in C.57BL females.

In some females from intra- and inter-strain matings, the spermatozoa present throughout the length of a single oviduct at 11.30 or 13.30 hours were counted from serial sections, excluding the cumulus clumps in which it proved impossible to distinguish spermatozoa. The great majority of the spermatozoa were situated immediately above the uterotubal junction, in the extramural junctura and lower isthmus. Very few were found in the upper isthmic and ampullary regions, even in mice killed at 13.30 hours. At 11.30 hours, four oviducts of $\mathrm{C} 3 \mathrm{H}$ females mated to males of their own strain contained respectively 125, 160, 172 and 292 spermatozoa, an order of magnitude lower than the numbers in the C57BL females, whether mated to C57BL males (1108, 2816 and 2970 spermatozoa) or C3H males (2300 and 5235 spermatozoa) The G3H females mated to C57BL males contained 590, 649 and 1480 spermatozoa. By 13.30 hours, the difference between the strains had greatly decreased, with counts for intra-strain matings of 985 and 1885 spermatozoa for the $\mathrm{C} 3 \mathrm{H}$ strain, and 2305 and 5390 for the C57BL strain.

The distribution of spermatozoa found in the oviducts in the present study, with the great majority immediately above the uterotubal junction, is similar to that reported for the hamster (Yanagimachi \& Chang, 1963) and rabbit (Braden, 1953; Harper, 1973). Braden (1953) suggested that the isthmus was a barrier to the passage of spermatozoa. Hunter \& Léglise (1971) directly confirmed Braden's suggestion for the pig, since surgical removal of the isthmus led to larger numbers of spermatozoa on the eggs and a much higher incidence of polyspermy. Harper (1973), who found 82 to $99 \%$ of rabbit oviducal spermatozoa still in the proximal isthmus $9 \frac{1}{2} \mathrm{hr}$ after insemination, comments that there is no obvious histological basis for their retention in this segment of the oviduct.

Our limited data indicate that the total number of spermatozoa in the oviducts within 2 to $3 \mathrm{hr}$ of mating is markedly less in $\mathrm{C} 3 \mathrm{H}$ intra-strain matings (100 to 300 spermatozoa per oviduct) than in matings of C57BL females (1000 to 5000 spermatozoa per oviduct). The C3H females mated to C57BL males may occupy an intermediate position. Few reports exist of the total number of spermatozoa in the oviducts of other species: Blandau \& Money 


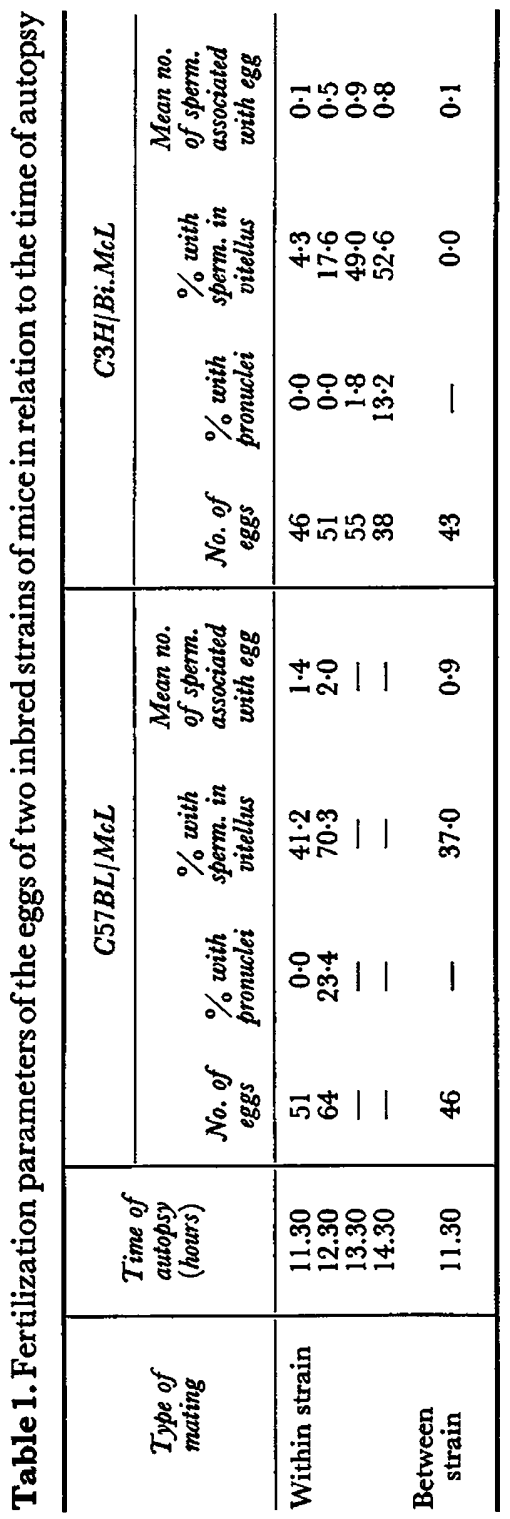


(1944) report a maximum of 200 in the rat $1 \mathrm{hr}$ after mating, while Braden (1953) found that the number in rabbits increased up to $6 \mathrm{hr}$ after mating, and then remained at about 5000 per oviduct.

We do not know whether the number of spermatozoa entering the oviducts determines the number reaching the site of fertilization. The greater number of spermatozoa found in association with the eggs in C57BL than in $\mathrm{C} 3 \mathrm{H}$ females suggests that this may be so. Harper (1973) concludes that the increase with time in the numbers of spermatozoa reaching the site of fertilization in the rabbit is due to a redistribution of spermatozoa within the oviduct rather than to reinforcements arriving from the uterus, since it is unaffected by ligation of the uterotubal junction.

An additional factor which may affect the number of spermatozoa associated with the eggs is the ease with which the cumulus mass can be penetrated. This too may be under genetic control since Krzanowska (1972) found that the time required to disperse the cumulus cells with hyaluronidase in vitro was significantly less in the C57BL strain than in the other strains tested.

It is probable that the delay in fertilization in the $\mathrm{C} 3 \mathrm{H}$ strain is related to the low number of spermatozoa associated with the eggs during the first few hours after mating. Penetration of the zona pellucida may also be slower in $\mathrm{C} 3 \mathrm{H}$ than in C57BL eggs, since treatment with pronase in vitro takes longer to lyse the zonae of $\mathrm{C} 3 \mathrm{H}$ than of C57BL eggs (P. Bowman, personal communication). This difference is unlikely to account for more than a fraction of the total difference in time of fertilization.

In summary, C57BL eggs are penetated by spermatozoa of either strain within 2 to $3 \mathrm{hr}$ of mating, but penetration of $\mathrm{C} 3 \mathrm{H}$ eggs takes several hours longer. A difference in the properties of the zona pellucida cannot be ruled out, but the major factor appears to be that spermatozoa are present in the vicinity of the eggs several hours earlier in C57BL than in C3H females. This may reflect the very much larger numbers of spermatozoa found in the lower part of the oviduct in C57BL mice.

We are grateful to the Ford Foundation for financial support.

\section{REFERENCES}

BlandaU, R. J. \& Money, W. L. (1944) Observations on the rate of transport of spermatozoa in the female genital tract of the rat. Anat. Rec. 90, 255.

Braden, A. W. H. (1953) Distribution of sperms in the genital tract of the female rabbit after coitus. Aust. F. biol. Sci. 6, 693.

Braden, A. W. H. (1958) Variation between strains of mice in phenomena associated with sperm penetration and fertilization. 7. Genet. 56, 37.

HARPER, M. J. K. (1973) Relationship between sperm transport and penetration of eggs in the rabbit oviduct. Biol. Reprod. 8, 441.

Hunter, R. H. F. \& LÉglise, P. G. (1971) Polyspermic fertilization following tubal surgery in pigs, with particular reference to the rôle of the isthmus. F. Reprod. Fert. 24, 233.

KRZANOwska, H. (1964) Time interval between copulation and fertilization in inbred lines of mice and their crosses. Folia biol., Krakbw, 12, 231.

Krzanowska, H. (1972) Rapidity of removal in vitro of the cumulus oophorus and the zona pellucida in different strains of mice. $\mathcal{F}$. Reprod. Fert. 31, 7.

MaLaren, A. \& Bowman, P. (1973) Genetic effects on the timing of early development in the mouse. F. Embryol. exp. Morph. 30, 491 .

Yanagimachi, R. \& Ghang, M. C. (1963) Sperm ascent through the oviduct of the hamster and rabbit in relation to the time of ovulation. $\mathcal{7}$. Reprod. Fert. $6,413$. 